\title{
IGF-IR determines the fates of BCR/ABL leukemia
}

\author{
Jingjing Xie ${ }^{1 \dagger}$, Xiaoli Chen ${ }^{2 \dagger}$, Junke Zheng ${ }^{2}$, Chunling $\mathrm{Li}^{1}$, Satomi Stacy ${ }^{2}$, Martin Holzenberger ${ }^{3}$, Xuemei Hu${ }^{1}$ \\ and Cheng Cheng Zhang ${ }^{1,2^{*}}$
}

\begin{abstract}
Background: The tyrosine kinase receptor insulin-like growth factor 1 receptor (IGF-IR) contributes to the initiation and progression of many types of malignancies. We previously showed that IGF-2, which binds IGF-IR, is an extrinsic factor that supports the ex vivo expansion of hematopoietic stem cells (HSCs). We also demonstrated that IGF-IR is not required for HSC activity in vivo.

Methods and results: Here we investigated the role of IGF-IR in chronic myeloid leukemia (CML) using the retroviral BCR/ABL transplantation mouse model. Existing antibodies against IGF-IR are not suitable for flow cytometry; therefore, we generated a fusion of the human IgG Fc fragment with mutant IGF-2 that can bind to IGF-IR. We used this fusion protein to evaluate mouse primary hematopoietic populations. Through transplantation assays with IGF-IR and IGF-IR cells, we demonstrated that IGF-IR is expressed on all mouse HSCs. The expression of IGF-IR is much higher on CML cells than on acute lymphoblastic leukemia (ALL) cells. The depletion of IGF-IR expression in BCR/ABL ${ }^{+}$cells led to the development of ALL (mostly T cell ALL) but not CML. Lack of IGF-IR resulted in decreased self-renewal of the BCR/ABL ${ }^{+}$ CML cells in the serial replating assay.
\end{abstract}

Conclusion: IGF-IR regulates the cell fate determination of $\mathrm{BCR}_{\mathrm{ABL}}{ }^{+}$leukemia cells and supports the self-renewal of CML cells.

Keywords: Leukemia, Chronic myeloid leukemia, Acute lymphoblastic leukemia, Hematopoietic stem cells, Tyrosine kinase receptor, BCR/ABL, IGF-IR

\section{Introduction}

Chronic myeloid leukemia (CML) is a hematopoietic malignancy that results from the $\mathrm{t}(9 ; 22)(\mathrm{q} 34 ; \mathrm{q} 11)$ Philadelphia $(\mathrm{Ph})$ chromosome translocation, which produces the BCR/ ABL fusion oncogene [1-3]. Tyrosine kinase inhibitors (TKIs) effectively treat symptoms of CML patients, but the disease is not curable in most cases. Both BCR/ABL dependent and independent mechanisms contribute to TKI resistance. The BCR/ABL dependent resistance may result from duplication, overamplification, or mutation of the gene encoding BCR/ABL [4-7]. BCR/ABL independent resistance mechanisms result from drug efflux or influx or activation of alternative signaling pathways $[8,9]$. CMLinitiating cells (CML-ICs) in patients have been shown to be insensitive to TKIs [10]. Novel targets in CML-ICs

\footnotetext{
*Correspondence: alec.zhang@utsouthwestern.edu

${ }^{\dagger}$ Equal contributors

'Taishan Scholar Immunology Program, Binzhou Medical University, 264003

Yantai, Shandong, China

${ }^{2}$ Departments of Physiology and Developmental Biology, University of Texas Southwestern Medical Center, 75390 Dallas, TX, USA

Full list of author information is available at the end of the article
}

must be identified in order to develop therapeutic strategies to eliminate CML.

Insulin-like growth factor 1 receptor (IGF-IR) is a receptor tyrosine kinase. IGF-IR is a homodimer of $\alpha$ and $\beta$ subunits that recognizes ligands IGF-1 and IGF-2 [11]. IGF-IR-mediated signaling is important for normal development and contributes to the initiation and progression of many types of solid malignancies [11-14]. IGF-IR also contributes to development of hematopoietic malignancies including acute myeloid leukemia (AML), T cell acute lymphoblastic leukemia (T-ALL), multiple myeloma, and CML. Autocrine IGF signaling, mediated through IGF-IR, supports the growth and survival of AML cells via the phosphoinositide 3-kinase/Akt pathway [15]. IGF-IR is also critical for the transformation of MLL-AF9 AML but is not required for AML propagation [16]. IGF-IR expression is essential for maintenance of T-ALL stem cells and is supported by Notch signaling $[17,18]$. Inhibition of IGFIR signaling has a significant antitumor effect on multiple myeloma in a xenograft model [19]. BCR/ABL upregulates IGF-1 expression and IGF-1 is overexpressed in human 
CML samples. Aberrant autocrine IGF signaling supports progression to the CML blast crisis phase [20].

We previously reported that IGF signaling supports hematopoietic stem cell (HSC) expansion [21]. However, IGF-IR is dispensable for HSC activity in mice [22]. Here we sought to test whether a signaling that is dispensable to normal HSCs is important to the activity of malignant CML cells. We found that IGF-IR is highly expressed on HSCs, and levels of IGF-IR were much higher on CML cells than on ALL cells. Although IGF-IR is dispensable for activity of normal HSCs, it is critical to BCR/ABL leukemia fate determination and self-renewal of CML cells. Loss of IGF-IR in $\mathrm{Ph}^{+}$cells resulted in development of ALL.

\section{Results}

\section{IGF-IR is expressed on the surface of HSCs}

We previously showed that IGF-2 stimulates ex vivo expansion of HSCs [21]. There are three known receptors for IGF-2: IGF type 1 receptor (IGF-IR), IGF type 2 receptor (IGF-IIR), and insulin receptor. Using a fusion of IGF-2 and IgG Fc as an affinity reagent, we previously showed that all repopulating HSCs bound IGFs [21]. Because existing antibodies against IGF-IR are not suitable for flow cytometry, we were unable to determine whether IGF-IR was expressed on HSCs. Thus we generated a fusion protein of IgG Fc with a mutant IGF-2 that can bind only to IGF-IR but not IGF-IIR (Figure 1A). As described previously [23], Ala and Leu replacements of Arg54 and Arg55, respectively, led to an IGF2 (Arg-IGF2) incapable of binding to IGF-IIR. We used FACS to sort cells based on their abilities to bind to this mutant IGF2 (Figure 1B). The lysates of these sorted cells were analyzed by western blot with antibodies against IGF-IR, confirming that ArgIGF2 specifically binds to IGF-IR (Figure 1C). About $30 \pm$ $6 \%$ or $18 \pm 5 \%$ of total fetal liver or bone marrow cells in

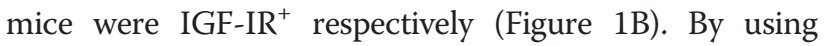
sorted IGF-IR ${ }^{+}$and IGF-IR ${ }^{-}$cells in comparative longterm bone marrow repopulation assays, we demonstrated that all mouse fetal liver and adult bone marrow HSCs express IGF-IR (Figure 1D). Moreover, we used flow cytometry to show that, all $\mathrm{Lin}^{-} \mathrm{Sca}-1^{+} \mathrm{Kit}^{+}$cells are IGF-IR ${ }^{+}$ (Figure 1E). Although approximately $50 \%$ of $\mathrm{Lin}^{-} \mathrm{Sca}-1^{+}$ cells are IGF-IR ${ }^{+}$(not shown), all of the repopulating activity of $\mathrm{Lin}^{-} \mathrm{Sca}-1^{+}$cells resided in the fetal liver and bone marrow $\mathrm{Lin}^{-} \mathrm{Sca}-1^{+} \mathrm{IGF}-\mathrm{hFc}^{+}$fraction (Figure 1F). That mouse HSCs express IGF-IR suggests a role of IGF signaling in physiology and pathogenesis of HSCs.

\section{IGF-IR regulates $B C R / A B L$ leukemia fates}

The fact that IGF-IR is expressed on HSCs but does not play an essential role in regulation of HSC repopulation in vivo led us to investigate the role of IGF-IR-mediated signaling in hematopoietic malignancies. IGF-IR supports hematopoietic malignancies including AML, T-ALL, and multiple myeloma [15-19]. The presence of the BCR/ABL fusion is also correlated with elevated IGF-1 expression in human CML samples. Autocrine IGF signaling supports progression of the CML blast crisis phase, and, conversely, inhibition of IGF-1R reduces viability and proliferation of BCR-ABL ${ }^{+}$cells [20]. We therefore used a retroviral BCRABL transplantation mouse model [24-26] to further study the role of IGF-IR in regulation of BCR/ABL leukemia development. Wild-type (WT) or IGF-IR-null donor fetal liver Lin $^{-}$cells infected by retroviral BCR-ABL-IRES-GFP were used to induce leukemia. The lack of IGF-IR did not change the level of expression of the mRNA encoding BCR/ABL (Figure 2A). We next investigated whether IGFIR was required for the induction of leukemia by $B C R /$ ABL. Mice transplanted with BCR/ABL-transduced WT and IGF-IR cells had similar $\mathrm{GFP}^{+}$cells at 3 months (Figure 2B), suggesting IGF-IR is not essential for BCR/ ABL leukemia propagation. Consistently, IGF-IR deficiency did not cause a significant alteration in the survival of leukemic mice (Figure 2C). However, there was a much less severe infiltration of IGF-IR-null myeloid leukemia cells into the lung, liver, and spleen compared to levels of WT cells (Figure 2D-E), suggesting that IGF-IR does impact leukemia development.

Samples from mice transplanted with IGF-IR-null BCR/ ABL cells and those transplanted with WT BCR/ABL cells were analyzed by flow cytometry and cytospin staining for cells characteristic of CML and ALL (Figure 3A-B). Over $60 \%$ of WT BCR/ABL-infected cells developed into CML, and the rest developed into ALL. In contrast, all IGF-IRnull BCR/ABL cells resulted in ALL, with T-ALL observed in most cases (Figure 3C-D, 26 out of 28 cases were T-ALL). While the mice with the null leukemia might show a delayed trend of death, the difference in types of leukemia did not significantly alter the survival of mice infected with WT and IGF-IR-null BCR/ABL cells (Figure 3D).

In addition to infecting fetal liver $\mathrm{Lin}^{-}$cells, we also followed the published protocols $[25,26]$ to infect 5 -FU treated bone marrow cells with BCR/ABL-IRES-GFP retrovirus. Concordant with reported results, all the recipient mice transplanted with $B C R / A B L$ virus infected WT cells developed CML-like disease. Three recipient mice survived 20, 29, and 31 days respectively. In contrast, all the recipient mice transplanted with IGF-IRnull BCR/ABL cells developed ALL and survived 29, 35, and 46 days respectively. These results confirmed that the deficiency of IGF-IR results in alteration of fates of $\mathrm{BCR} / \mathrm{ABL}$ induced leukemia.

\section{Deficiency in IGF-IR decreases self-renewal of CML cells}

We next assessed whether IGF-IR regulates self-renewal of $\mathrm{BCR} / \mathrm{ABL}$ leukemia cells. IGF-IR deficiency led to 


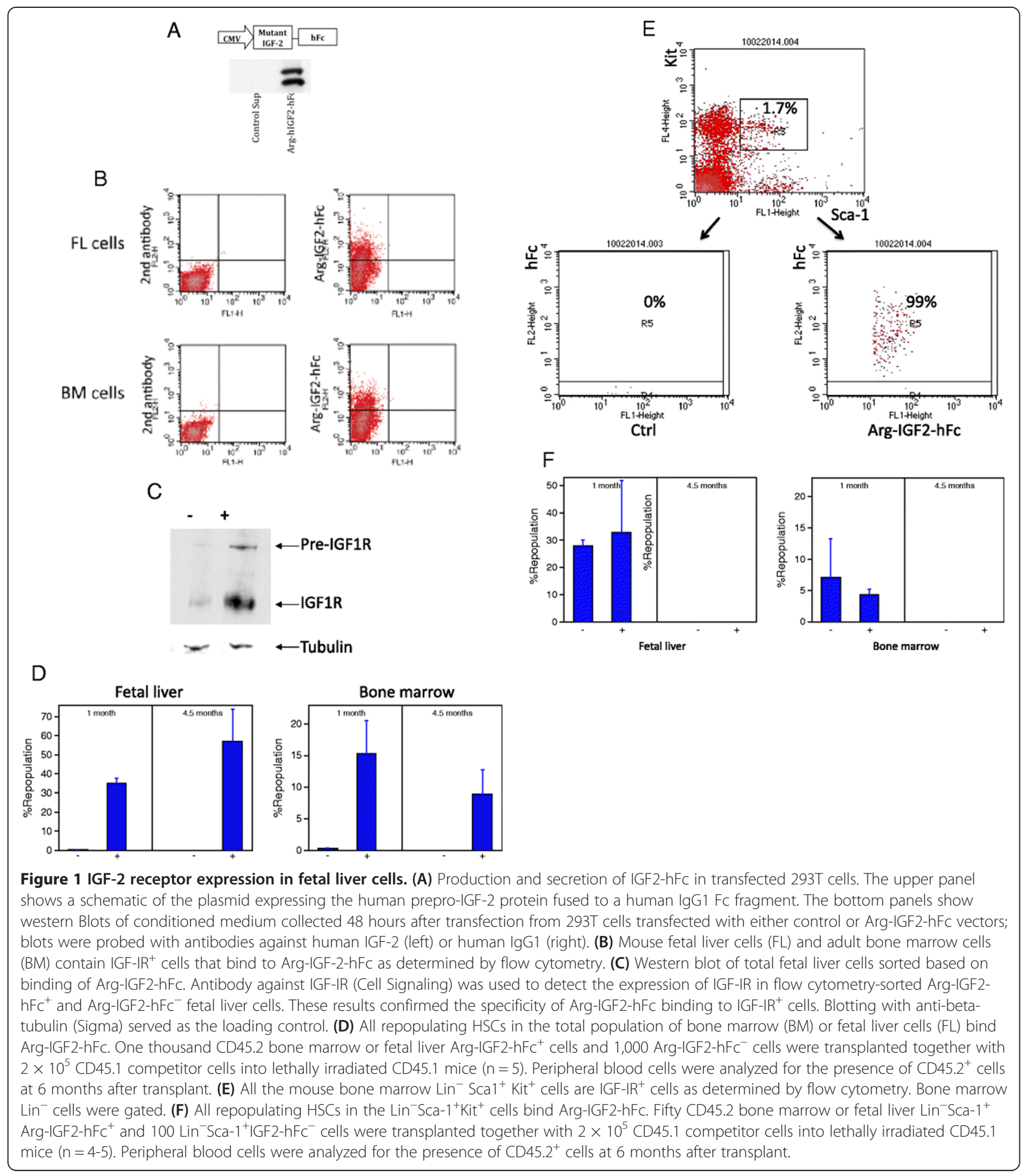

dramatically decreased LSK percentages in leukemia bone marrow (Figure 4A-B). Colony formation assays showed that WT and IGF-IR-null BCR/ABL cells had similar colony forming abilities in primary plating; however, IGF-IR-null cells had decreased colony forming capacity upon replating (Figure $4 \mathrm{C}$ ). These results suggest that IGF-IR supports the self-renewal of CML cells. IGF-IR was expressed at significantly higher levels by $\mathrm{BCR} / \mathrm{ABL}^{+} \mathrm{CML}$ cells than by T-ALL or B-ALL cells (Figure 4D-E). Together, our results suggest that the lack of IGF-IR on CML cells shifts BCR/ABL leukemia cell fate from CML to ALL. 


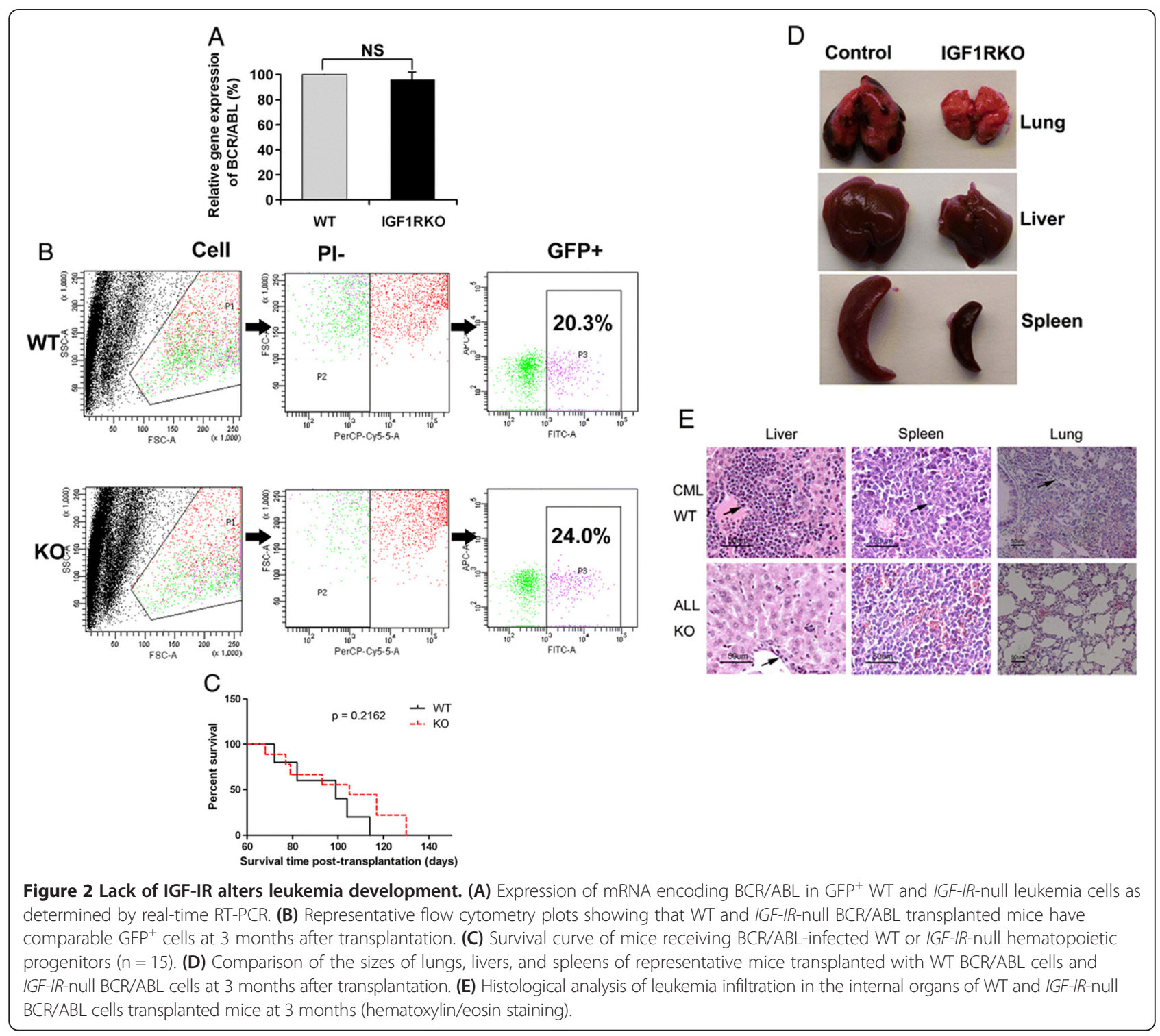

\section{Discussion}

Previously, we showed that IGF-2 stimulates the ex vivo expansion of HSCs [21]. IGF-IR is not required for in vivo repopulation of HSCs, however [22]. Here, we demonstrated that IGF-IR is highly expressed on HSCs and CML cells but is only expressed at low levels on ALL cells. Although IGF-IR is dispensable for normal HSC maintenance, it is critical to BCR/ABL leukemia fate determination. Loss of IGF-IR in $\mathrm{Ph}^{+}$leukemia resulted in development of ALL. That IGF-IR supports CML cell self-renewal is concordant with the reported function of IGF-1R in self-renewal of embryonic stem cells [27] and in ex vivo expansion of HSCs [21]. Like other signaling pathways, including $\mathrm{Wnt} / \beta$-catenin and Hedgehog [28], the IGF-IR signaling system appears to be dispensable in normal HSCs but activated in leukemia cells. Such signaling pathways contribute specifically to cancer initiation or progression.

An important question is whether IGF-IR plays different roles in different types of cells. Our and others' studies clearly indicated that IGF-IR has distinct functions in different contexts. It is well documented that IGF-IR is important in a variety of functions in different cancer types including proliferation, adhesion, migration, survival, and metastases [12]. While it is not required for in vivo HSC repopulation, IGF-IR is required for various leukemia development. As shown here, IGF-IR is necessary for fate determination and self-renewal of CML cells and blocking IGF-IR signaling inhibits CML development but leads to $\mathrm{Ph}^{+}$ALL. Consistently, IGF-IR transforms MLL-AF9 AML progenitors but does not to stimulate leukemia propagation, and blocking IGF-IR 


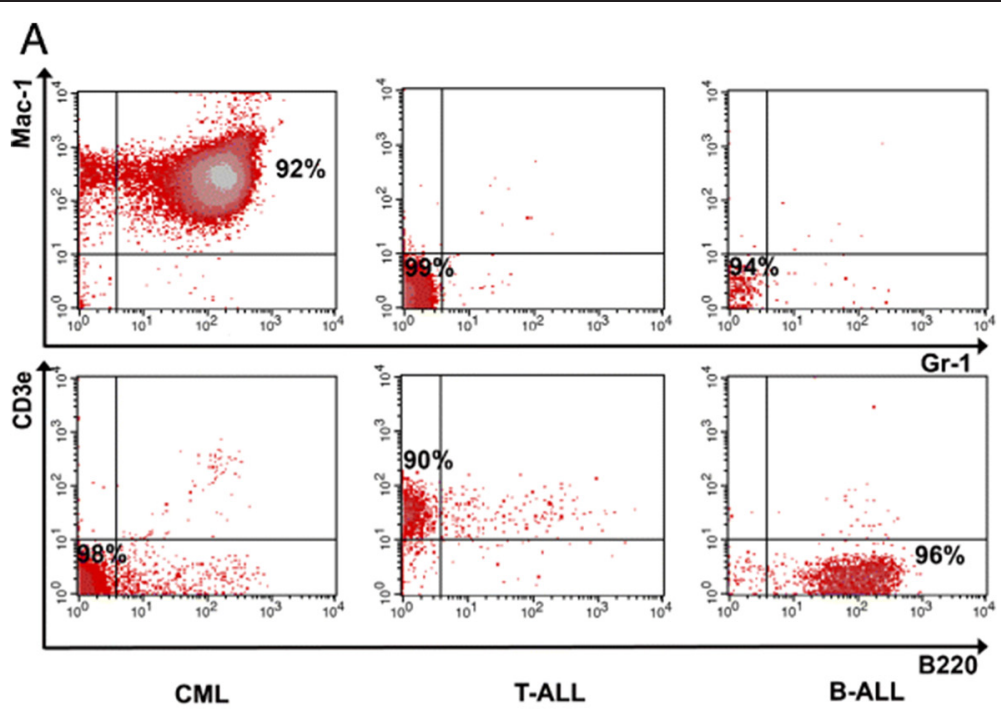

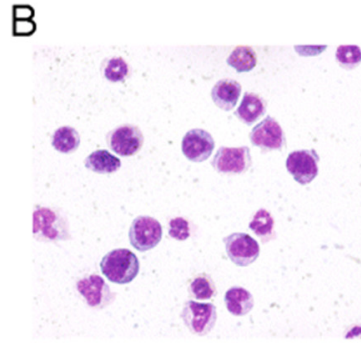

CML

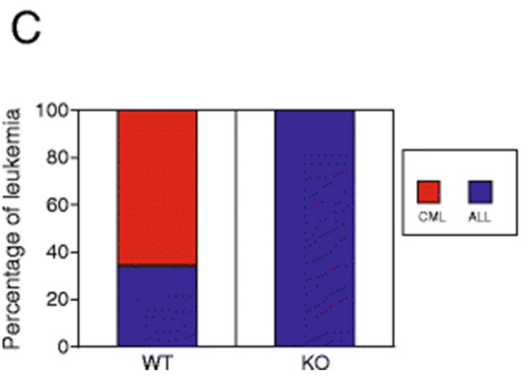

ALL

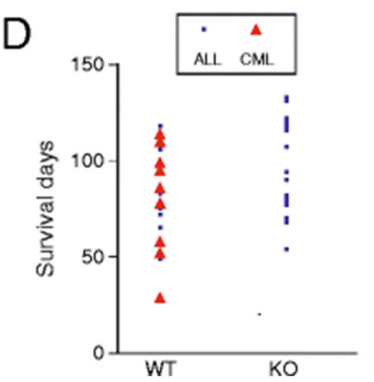

Figure 3 IGF-IR deficiency alters BCR/ABL leukemia fates. (A) Representative flow cytometry plots showing CML, T-ALL, and B-ALL cells in mice transplanted with WT or IGF-IR-null BCR/ABL cells. (B) Cytospin staining of CML and ALL in mice transplanted with WT or IGF-IR-null BCR/ABL cells. (C) Percentages of different types of leukemia developed by mice transplanted with BCR/ABL-infected WT or IGF-IR-null hematopoietic progenitors. (D) Survival curves of mice receiving BCR/ABL-infected WT or IGF-IR-null hematopoietic progenitors that developed different types of leukemia ( $\mathrm{n}=15$ ).

signaling inhibits AML development [16]. IGF-IR has different roles in different types of T-ALL. While high levels of IGF-IR support the activity of T-LBL stem cells [17], it is clear from our study that BCR/ABL driven T-ALL does not express a significant level of IGF-IR and IGF-IR is not required for $\mathrm{Ph}^{+}$T-ALL development.

This study raises provocative questions regarding extrinsic signaling for leukemia stem cells. Is IGF-IR signaling in CML cells independent of BCR/ABL-induced signaling? How does IGF signaling, together with other extrinsic and intrinsic pathways (IL-6, Wnt, Hedgehog, BMPs, selectin, TGF- $\beta$, Alox5, CD25, among others) [9,28-33], regulate the fates of CML cells including selfrenewal, differentiation, apoptosis, and migration? Given extensive aberrant signaling in CML cells, we expect that the combined use of TKIs and inhibition of a limited number of key extrinsic pathways, including IGF-IR signaling, will lead to the development of novel strategies for treating CML. 
A
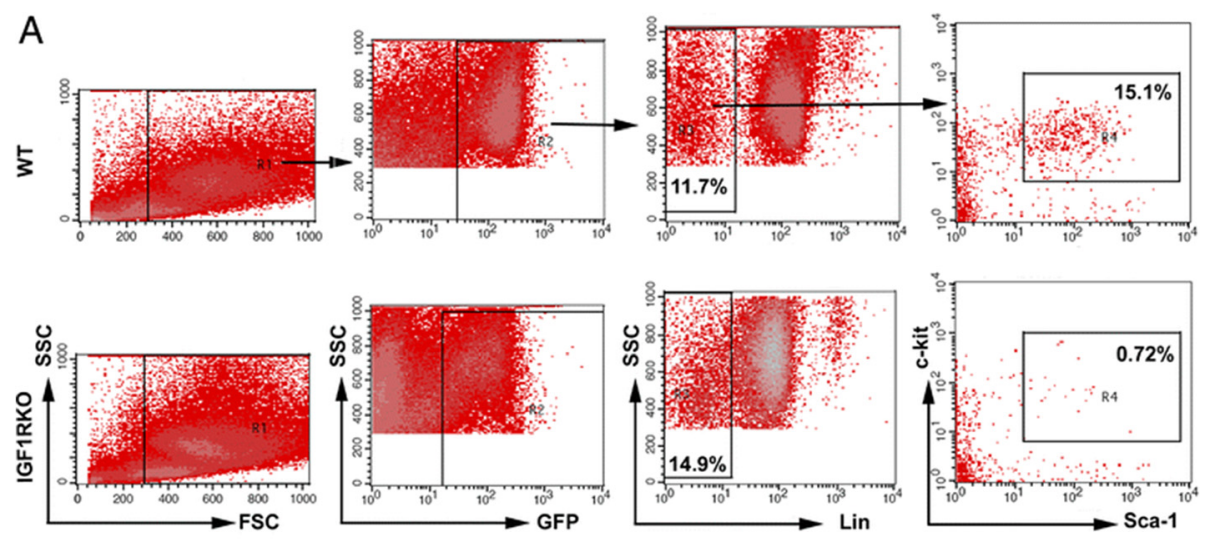

B
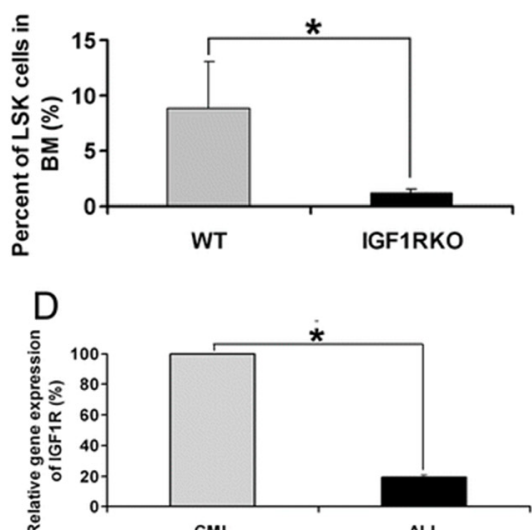

C
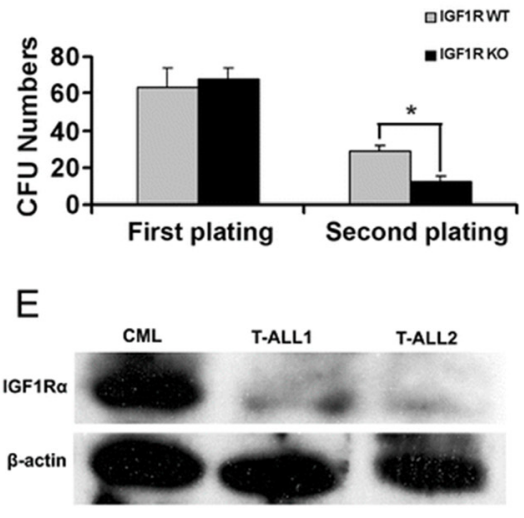

Figure 4 Lack of IGF-IR decreases self-renewal of CML cells. (A-B) LSK percentages dramatically decreased in leukemia bone marrow from mice transplanted with IGF-IR-null compared to WT BCR/ABL cells as shown in (A) representative flow cytometry plots and (B) as summarized in the bar graph. (C) IGF-IR-null leukemia cells have dramatically decreased CFU forming ability in second replating ( $n=3$ ). (D-E) Expression of IGF-IR in WT and IGF-IR-null BCR/ABL leukemia cells as determined by (D) real-time RT-PCR and (E) western blotting.

\section{Conclusion}

We developed a novel method to mark IGF-IR on the surface of cells. Using this flow cytometry-based method and reconstitution analyses, we found that IGF-IR is expressed on all mouse HSCs. The expression of IGF-IR was dramatically higher on CML cells than on ALL cells. The knockout of IGF-IR in BCR/ABL ${ }^{+}$ cells led to the development of ALL (mostly T-ALL) but not CML. Lack of IGF-IR resulted in decreased self-renewal of the $\mathrm{BCR} / \mathrm{ABL}^{+} \mathrm{CML}$ cells. Therefore, IGF-IR directs $\mathrm{BCR} / \mathrm{ABL}^{+}$leukemia cells toward the myeloid fate. Because IGF-IR is dispensable for the activity of HSCs but regulates BCR/ABL leukemia cell fates and supports self-renewal of CML cells, targeting IGF-IR may be an ideal anti-leukemia strategy. Inhibition of the IGF-IR axis may contribute to the development of future combination therapies that selectively target multiple key signaling pathways unique to $\mathrm{CML}$ cells.

\section{Methods}

Animals

C57 BL/6 CD45.2 and CD45.1 mice were purchased from Jackson Lab or National Cancer Institute. IGF-IR ${ }^{+/-}$mice as previously described [34] were in a pure C57BL/6 background. Mice were maintained at the University of Texas Southwestern Medical Center animal facility. All animal experiments were performed with the approval of UT Southwestern Committee on Animal Care.

\section{Expression of IGF-2-hFc}

Originally IGF2-hFc was constructed by fusing IGF-2 and human IgG1 Fc under the control of CMV promoter [21]. The QuikChange Mutagenesis kit (Stratagene) was used to substitute Arg54-Arg55 with Ala-Leu to produce ArgIGF2-hFc. The plasmid was transfected into 293T cells using Lipofectamine 2000 (Invitrogen). Conditioned medium was collected 48 hours after transfection. The conditioned medium with about $1 \mu \mathrm{g} / \mathrm{ml}$ of Arg-IGF-2- 
$\mathrm{hFc}$ as determined by western blotting was used in the subsequent staining of fetal liver or bone marrow cells.

\section{Flow cytometry, immunohistochemistry, and cytospin}

Flow cytometry, immunohistochemistry, and cytospin were performed as we described previously $[35,36]$.

Lin $^{-} \mathrm{Sca}-1^{+} \mathrm{Kit}^{+}$cells were detected or sorted as described [37-39]. Ala-IGF2-hFc ${ }^{+}$and Ala-IGF2-hFc cells were stained and sorted using a protocol similar to that described previously [21]. Briefly, $10^{7}$ cells were resuspended in $1 \mathrm{ml}$ of conditioned medium (with $\sim 1 \mu \mathrm{g} / \mathrm{ml}$ Arg-IGF2-hFc as determined by western blotting) at $4{ }^{\circ} \mathrm{C}$ for 30 minutes followed by staining with antihuman IgG1 Fc-PE (Jackson ImmunoResearch). The conditioned medium from mock transfected cells was used as a control. When necessary, the co-staining of biotinylated $\mathrm{Lin}^{+}$antibody cocktail followed by streptavidin-APC and anti-Sca-1-FITC was performed before sorting $\mathrm{Lin}^{-} \mathrm{Sca}-$ $1^{+}$IGF2-hFc ${ }^{+}$and Lin $^{-} \mathrm{Sca}-1^{+} \mathrm{IGF} 2-\mathrm{hFc}^{-}$cells in a FACSAria sorter.

For reconstitution analyses, peripheral blood cells were collected by retro-orbital bleeding. Red blood cells were lysed and stained with anti-CD45.2-FITC, anti-CD45.1PE, anti-Thy1.2-PE, anti-B220-PE, anti-Mac1-PE, antiGr1-PE, or anti-Ter119-PE monoclonal antibodies (BD Pharmingen) as we described [39,40]. FACS analyses were performed on a FACSCalibur ${ }^{\circ}$ instrument.

For flow cytometry analysis of leukemia cells, peripheral blood or bone marrow cells were stained with antiLineage-Biotin (followed by streptavidin-APC), antiMac1-APC, anti-Gr1-PE, anti-CD3-APC, anti-B220-PE, or anti-Kit-PE monoclonal antibodies (BD Pharmingen). Cell cycle status was determined by propidium iodide staining. For analysis of apoptosis, cells were stained with PE-conjugated anti-annexin V and 7-AAD (BD Pharmingen) according to the manufacturer's instructions.

\section{Competitive reconstitution analysis}

Indicated numbers of CD45.2 donor cells were mixed with $1 \times 10^{5}$ freshly isolated CD45.1 competitor bone marrow cells, which were then injected intravenously via the retro-orbital route into CD45.1 mice previously irradiated with a total dose of 10 Gy. To measure reconstitution of transplanted mice, peripheral blood was collected by retro-orbital bleeding at the indicated times post-transplant and the presence of $\mathrm{CD} 45.1^{+}$and CD $45.2^{+}$cells in lymphoid and myeloid compartments were measured as we described [39].

\section{CML mouse model}

The retrovirus transplantation CML mouse model was prepared essentially as described [25,26]. Bone marrow cells from 5-FU treated C57BL/6 mice or C57BL/6 fetal liver Lin $^{-}$cells were infected with retrovirus carrying
MSCV-BCR/ABL-IRES-GFP. The transduced cells $(5 \times$ $10^{5}$ ) were transplanted intravenously into lethally irradiated (10 Gy) C57BL/6 recipients.

\section{Colony forming unit (CFU) assays}

Cells from leukemia mice were plated in methylcellulose (M3534, Stem Cell Technologies) for CFU-GM assays according to the manufacturer's protocols and our previously published protocol $[35,37,39]$. After 7 days, 2000 cells from three dishes were used for secondary replating.

\section{Western blotting}

Cell lysates (100 $\mu \mathrm{g}$ samples) were separated by electrophoresis on a 4-12\% SDS-polyacrylamide gel, and the proteins were electroblotted onto a nitrocellulose membrane. The membrane was probed with primary antibody for 1 hour at room temperature and then incubated with horseradish peroxidase-conjugated secondary antibody, which was detected with the chemiluminescence SuperSignal kit (Pierce).

\section{Quantitative RT-PCR}

Total RNA was isolated from FACS-collected cells. First-strand cDNA was synthesized using SuperScript II RT (Invitrogen). Samples were analyzed in triplicate 25$\mu \mathrm{l}$ reactions (300 $\mathrm{nM}$ each primer, $12.5 \mu \mathrm{l}$ of Master mix) as adapted from the standard protocol provided in SYBR Green PCR Master Mix and RT-PCR Protocols provided by Applied Biosystems. Primers were purchased from Qiagen or Sigma. The default PCR protocol was used on an Applied Biosystems Prism 7000 Sequence Detection System. The mRNA level in each population was normalized to the level of $\beta$-actin RNA transcripts present in the same sample as described previously [41].

\section{Statistical analyses}

Data are expressed as means \pm SEM. Data were analyzed by Student's $t$ test and were considered statistically significant if $p<0.05$. The survival rates of the two groups were analyzed using a log-rank test.

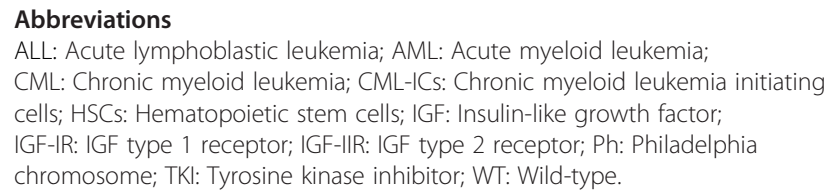

Competing interest

The authors declare no competing financial interests.

Authors' contributions

$J X, X C, J Z$, and CCZ contributed to experimental design, performed experiments, interpreted data, and contributed to writing of the manuscript. $\mathrm{CL}, \mathrm{SS}, \mathrm{MH}$, and $\mathrm{XH}$ contributed to experimental performance and interpretation. All authors read and approved the final manuscript. 


\section{Authors' information}

C.C.Z. is an associate professor at UT Southwestern Medical Center, focusing on the roles of secreted proteins and cell surface receptors in regulation of the cell fates of hematopoietic stem cells and leukemia cells.

\section{Acknowledgments}

We would like to thank Dr. Richard A. Van Etten for the MSCV-BCR/ABL (p210)-IRES-GFP vector. Support of this project was from NIH grant 1R01CA172268, Leukemia \& Lymphoma Society Awards LLS\#1024-14 and LLS\#6024-14-01, CPRIT RP140402, and Taishan Scholar Program.

\section{Author details}

${ }^{1}$ Taishan Scholar Immunology Program, Binzhou Medical University, 264003 Yantai, Shandong, China. ${ }^{2}$ Departments of Physiology and Developmental Biology, University of Texas Southwestern Medical Center, 75390 Dallas, TX, USA. ${ }^{3}$ INSERM and Sorbonne Universities, UPMC, Research Center UMR938, 75012 Paris, France.

\section{Received: 6 November 2014 Accepted: 5 January 2015 Published online: 04 February 2015}

\section{References}

1. Konopka JB, Watanabe SM, Witte ON. An alteration of the human c-ab protein in K562 leukemia cells unmasks associated tyrosine kinase activity. Cell. 1984;37:1035-42.

2. Shtivelman E, Lifshitz B, Gale RP, Canaani E. Fused transcript of abl and bcr genes in chronic myelogenous leukaemia. Nature. 1985;315:550-4

3. Daley GQ, Van Etten RA, Baltimore D. Induction of chronic myelogenous leukemia in mice by the P210bcr/abl gene of the Philadelphia chromosome. Science. 1990;247:824-30.

4. Gorre ME, Mohammed M, Ellwood K, Hsu N, Paquette R, Rao PN, et al. Clinical resistance to STI-571 cancer therapy caused by BCR-ABL gene mutation or amplification. Science. 2001;293:876-80.

5. Hochhaus A, Kreil S, Corbin AS, La Rosee P, Muller MC, Lahaye T, et al, Molecular and chromosomal mechanisms of resistance to imatinib (STI571) therapy. Leukemia. 2002;16:2190-6.

6. Willis SG, Lange T, Demehri S, Otto S, Crossman L, Niederwieser D, et al. High-sensitivity detection of BCR-ABL kinase domain mutations in imatinibnaive patients: correlation with clonal cytogenetic evolution but not response to therapy. Blood. 2005;106:2128-37.

7. O'Hare T, Eide CA, Deininger MW. Bcr-Abl kinase domain mutations, drug resistance, and the road to a cure for chronic myeloid leukemia. Blood. 2007;110:2242-9.

8. NestaldeMoraes G, Souza PS, Costas FC, Vasconcelos FC, Reis FR, Maia RC. The interface between BCR-ABL-dependent and -independent resistance signaling pathways in chronic myeloid leukemia. Leuk Res Treatment. 2012;2012:671702.

9. O'Hare T, Zabriskie MS, Eiring AM, Deininger MW. Pushing the limits of targeted therapy in chronic myeloid leukaemia. Nat Rev Cancer. 2012;12:513-26

10. Corbin AS, Agarwal A, Loriaux M, Cortes J, Deininger MW, Druker BJ. Human chronic myeloid leukemia stem cells are insensitive to imatinib despite inhibition of BCR-ABL activity. J Clin Invest. 2011;121:396-409.

11. Pollak MN, Schernhammer ES, Hankinson SE. Insulin-like growth factors and neoplasia. Nat Rev Cancer. 2004;4:505-18.

12. LeRoith D, Roberts Jr CT. The insulin-like growth factor system and cancer. Cancer Lett. 2003;195:127-37.

13. Baker J, Liu JP, Robertson EJ, Efstratiadis A. Role of insulin-like growth factors in embryonic and postnatal growth. Cell. 1993;75:73-82.

14. Khandwala HM, McCutcheon IE, Flyvbjerg A, Friend KE. The effects of insulin-like growth factors on tumorigenesis and neoplastic growth. Endocr Rev. 2000;21:215-44.

15. Doepfner KT, Spertini O, Arcaro A. Autocrine insulin-like growth factor-I signaling promotes growth and survival of human acute myeloid leukemia cells via the phosphoinositide 3-kinase/Akt pathway. Leukemia. 2007;21:1921-30.

16. Jenkins CR, Shevchuk OO, Giambra V, Lam SH, Carboni JM, Gottardis MM, et al. IGF signaling contributes to malignant transformation of hematopoietic progenitors by the MLL-AF9 oncoprotein. Exp Hematol. 2012;40:715-23. e716.
17. Weng AP, Ferrando AA, Lee W, Morris JP, Silverman LB, Sanchez-lrizarry C, et al. Activating mutations of NOTCH1 in human T cell acute lymphoblastic leukemia. Science. 2004;306:269-71.

18. Gusscott S, Kuchenbauer F, Humphries RK, Weng AP. Notch-mediated repression of miR-223 contributes to IGF1R regulation in T-ALL. Leuk Res. 2012;36:905-11.

19. Mitsiades CS, Mitsiades NS, McMullan CJ, Poulaki V, Shringarpure R, Akiyama $M$, et al. Inhibition of the insulin-like growth factor receptor-1 tyrosine kinase activity as a therapeutic strategy for multiple myeloma, other hematologic malignancies, and solid tumors. Cancer Cell. 2004;5:221-30.

20. Lakshmikuttyamma A, Pastural E, Takahashi N, Sawada K, Sheridan DP, DeCoteau JF, et al. Bcr-Abl induces autocrine IGF-1 signaling. Oncogene. 2008;27:3831-44.

21. Zhang CC, Lodish HF. Insulin-like growth factor 2 expressed in a novel fetal liver cell population is a growth factor for hematopoietic stem cells. Blood. 2004;103:2513-21.

22. Huynh H, Zheng J, Umikawa M, Zhang C, Silvany R, lizuka S, et al. IGF binding protein 2 supports the survival and cycling of hematopoietic stem cells. Blood. 2011;118:3236-43.

23. Sakano K, Enjoh T, Numata F, Fujiwara H, Marumoto $Y$, Higashihashi N, et al. The design, expression, and characterization of human insulin-like growth factor II (IGF-II) mutants specific for either the IGF-II/cation-independent mannose 6-phosphate receptor or IGF-I receptor. J Biol Chem. 1991;266:20626-35.

24. Krause DS, Lazarides K, von Andrian UH, Van Etten RA. Requirement for CD44 in homing and engraftment of BCR-ABL-expressing leukemic stem cells. Nat Med. 2006:12:1175-80.

25. Zhang X, Ren R. Bcr-Abl efficiently induces a myeloproliferative disease and production of excess interleukin-3 and granulocyte-macrophage colonystimulating factor in mice: a novel model for chronic myelogenous leukemia. Blood. 1998;92:3829-40.

26. Li S, Ilaria Jr RL, Million RP, Daley GQ, Van Etten RA. The P190, P210, and $\mathrm{P} 230$ forms of the BCR/ABL oncogene induce a similar chronic myeloid leukemia-like syndrome in mice but have different lymphoid leukemogenic activity. J Exp Med. 1999;189:1399-412.

27. Bendall SC, Stewart MH, Menendez P, George D, Vijayaragavan K, Werbowetski-Ogilvie T, et al. IGF and FGF cooperatively establish the regulatory stem cell niche of pluripotent human cells in vitro. Nature. 2007:448:1015-21.

28. Crews $\mathrm{LA}$, Jamieson $\mathrm{CH}$. Selective elimination of leukemia stem cells: hitting a moving target. Cancer Lett. 2013;338:15-22.

29. Krause DS, Lazarides K, Lewis JB, von Andrian UH, Van Etten RA. Selectins and their ligands are required for homing and engraftment of BCR-ABL1+ leukemic stem cells in the bone marrow niche. Blood. 2014;123:1361-71.

30. Laperrousaz B, Jeanpierre S, Sagorny K, Voeltzel T, Ramas S, Kaniewski B, et al. Primitive CML cell expansion relies on abnormal levels of BMPS provided by the niche and on BMPRIb overexpression. Blood. 2013;122:3767-77

31. Reynaud D, Pietras E, Barry-Holson K, Mir A, Binnewies M, Jeanne M, et al. IL-6 controls leukemic multipotent progenitor cell fate and contributes to chronic myelogenous leukemia development. Cancer Cell. 2011;20:661-73.

32. Kobayashi Cl, Takubo K, Kobayashi H, Nakamura-Ishizu A, Honda H, Kataoka $K$, et al. The IL-2/CD25 axis maintains distinct subsets of chronic myeloid leukemia-initiating cells. Blood. 2014;123:2540-9.

33. Zhang CC. Novel signaling axis in CML-initiating cells. Blood. 2014:123:2443-5.

34. Holzenberger M, Dupont J, Ducos B, Leneuve P, Geloen A, Even PC, et al. IGF-1 receptor regulates lifespan and resistance to oxidative stress in mice. Nature. 2003;421:182-7.

35. Kocabas F, Zheng J, Thet S, Copeland NG, Jenkins NA, Deberardinis RJ, et al. Meis1 regulates the metabolic phenotype and oxidant defense of hematopoietic stem cells. Blood. 2012;120:4963-72.

36. Chen X, Zheng J, Zou Y, Song C, Hu X, Zhang CC. IGF binding protein 2 is a cell-autonomous factor supporting survival and migration of acute leukemia cells. J Hematol Oncol. 2013;6:72.

37. Zheng J, Umikawa M, Zhang $\mathrm{S}$, Huynh $\mathrm{H}$, Silvany $\mathrm{R}$, Chen BP, et al. Ex vivo expanded hematopoietic stem cells overcome the MHC barrier in allogeneic transplantation. Cell Stem Cell. 2011;9:119-30.

38. Zheng J, Umikawa M, Cui C, Li J, Chen X, Zhang C, et al. Inhibitory receptors bind ANGPTLs and support blood stem cells and leukaemia development. Nature. 2012;485:656-60. 
39. Zheng J, Lu Z, Kocabas F, Bottcher RT, Costell M, Kang X, et al. Profilin 1 is essential for retention and metabolism of mouse hematopoietic stem cells in bone marrow. Blood. 2014;123:992-1001.

40. Deng M, Lu Z, Zheng J, Wan X, Chen X, Hirayasu K, et al. A motif in LILRB2 critical for Angpt|2 binding and activation. Blood. 2014;124:924-35.

41. Huynh H, Llizuka S, Kaba M, Kirak O, Zheng J, Lodish HF, et al. IGFBP2 secreted by a tumorigenic cell line supports ex vivo expansion of mouse hematopoietic stem cells. Stem Cells. 2008;26:1628-35.

Submit your next manuscript to BioMed Central and take full advantage of:

- Convenient online submission

- Thorough peer review

- No space constraints or color figure charges

- Immediate publication on acceptance

- Inclusion in PubMed, CAS, Scopus and Google Scholar

- Research which is freely available for redistribution 